OPEN ACCESS

Edited by:

Daniela Ceccarelli,

Research Executive Agency,

European Commission, Belgium

Reviewed by:

Vera Manageiro,

Instituto Nacional de Saúde Doutor

Ricardo Jorge (INSA), Portugal Jeroen Dewult,

Ghent University, Belgium

Laura Vinue Santolalla,

Massachusetts General Hospital,

Harvard Medical School,

United States

*Correspondence:

Emilie Gay

emilie.gay@anses.fr

Specialty section:

This article was submitted to

Antimicrobials, Resistance

and Chemotherapy,

a section of the journal

Frontiers in Microbiology

Received: 25 June 2019

Accepted: 19 September 2019

Published: 09 October 2019

Citation:

Bourély C, Cazeau G, Jarrige N,

Jouy E, Haenni M, Lupo A,

Madec J-Y, Leblond A and Gay E

(2019) Co-resistance to Amoxicillin

and Tetracycline as an Indicator of Multidrug Resistance in Escherichia

coli Isolates From Animals.

Front. Microbiol. 10:2288.

doi: 10.3389/fmicb.2019.02288

\section{Co-resistance to Amoxicillin and Tetracycline as an Indicator of Multidrug Resistance in Escherichia coli Isolates From Animals}

\author{
Clémence Bourély ${ }^{1,2,3}$, Géraldine Cazeau², Nathalie Jarrige ${ }^{2}$, Eric Jouy4, Marisa Haenni ${ }^{5}$, \\ Agnese Lupo ${ }^{5}$, Jean-Yves Madec ${ }^{5}$, Agnès Leblond ${ }^{3}$ and Emilie Gay ${ }^{2 *}$
}

\begin{abstract}
${ }^{1}$ École Nationale des Services Vétérinaires, ENSV, VetAgro Sup, Marcy l'Étoile, France, ${ }^{2}$ ANSES, Laboratoire de Lyon, Unité Épidémiologie et Appui à la Surveillance, Université de Lyon, Lyon, France, ${ }^{3}$ EPIA, UMR 0346, Epidémiologie des Maladies Animales et Zoonotiques, INRA, VetAgro Sup, University of Lyon, Marcy l'Étoile, France, ${ }^{4}$ Laboratoire de Ploufragan-Plouzané-Niort, ANSES, Unité Mycoplasmologie Bactériologie Antibiorésistance, Université Bretagne Loire, Technopôle Saint-Brieuc Armor, Ploufragan, France, ${ }^{5}$ ANSES, Laboratoire de Lyon, Unité Antibiorésistance et Virulence Bactériennes, Université de Lyon, Lyon, France
\end{abstract}

Objectives: To examine the relevance of co-resistance to amoxicillin and tetracycline as an indicator of multidrug resistance (MDR) in animal health.

Methods: Escherichia coli isolates collected between 2012 and 2016 by the French surveillance network for antimicrobial resistance in diseased animals (RESAPATH) were analyzed. The proportions of MDR isolates and the proportions of isolates presenting co-resistance to amoxicillin and tetracycline were calculated for seven animal species (cattle, horse, dog, swine, poultry, duck, and turkey). The degree of agreement between these two proportions was estimated by calculating the kappa value.

Results: In total, 55,904 isolates were analyzed. MDR proportions were variable among animal species, ranging from $21.9 \%[20.2 ; 23.7]$ in horses to $56.0 \%[55.4 ; 56.7]$ in cattle. A similar situation was observed for proportions of isolates with co-resistance to amoxicillin and tetracycline, with the highest value for cattle 65.0\% [64.3; 65.6]. This co-resistance was also most often associated with resistance to other antibiotics, regardless of the animal species considered. Comparative analysis showed substantial agreement between MDR and this co-resistance, with a kappa value of 0.75 , all animal species considered.

Conclusion: Given the widespread use of penicillins and tetracyclines in animal health, co-resistance to amoxicillin and tetracycline could be an efficient indicator of MDR in E. coli isolates. Based on a specific resistance profile and not an arbitrary number of resistances compared with MDR, this potential indicator is also precise, convenient and suitable for routine use.

Keywords: antimicrobial resistance, multidrug resistance, E. coli, animal health, RESAPATH 


\section{INTRODUCTION}

Escherichia coli is the most frequently isolated pathogen in foodproducing animals and in pets and a major Gram-negative infectious agent for humans, being particularly implicated in urinary tract infections (Karam et al., 2016). E. coli is also considered to be an excellent sentinel of antimicrobial resistance for a wide range of animal species (De Graef et al., 2004; Aarestrup et al., 2008). Characterization of resistance in E. coli isolates include the assessment of their multidrug resistance (MDR), which should follow a standard definition.

Schwarz et al. (2010) proposed a general definition of MDR in veterinary medicine: $M D R$ is the acquired resistance to at least one antibiotic in three or more antibiotic categories (Schwarz et al., 2010). Because MDR status is based on the number of resistances, it is directly related to the total number of antibiotic categories selected for analysis (Magiorakos et al., 2012). However in the literature, regardless of the bacterial species considered, several definitions are used with no consensus regarding the number of antibiotic categories to take into account or the threshold to define MDR, i.e., the number of acquired resistances. Some authors take into account five acquired resistances (Strand et al., 2014; Aperce et al., 2016), whereas others consider only two (Cummings et al., 2015) or do not even specify which definition they use (Ewers et al., 2014). Therefore, assessment of MDR is inconsistent across studies and the variability of definitions hinders comparing studies (Cohen et al., 2008). To address these limitations, the MDR definition should be supplemented with an indicator describing a specific antibiotic resistance profile, i.e., co-resistance to several antibiotics.

In E. coli isolates from animals, resistances to amoxicillin and tetracycline are among the most frequently encountered resistances all over the world (Chen et al., 2014; Hanon et al., 2015; Boireau et al., 2018b; EFSA and ECDC, 2018). Furthermore, penicillins and tetracyclines are the most frequently used antibiotics in veterinary medicine in Europe (EMA and ESVAC, 2018). Therefore, the aim of this study was to examine if co-resistance to amoxicillin and tetracycline can be an indicator of MDR in animal health.

\section{MATERIALS AND METHODS}

This study was performed using data from the RESAPATH, the French established national surveillance network for antimicrobial resistance (AMR) in bacteria from diseased animals. The RESAPATH collects results from antimicrobial susceptibility testing performed routinely by French veterinary laboratories. Even if each laboratory has its own strategy for bacterial identification, API galleries are often used and the biggest ones use Maldi-TOF. All laboratories perform antimicrobial susceptibility testing by the disk diffusion method following the veterinary recommendations of the Antibiogram Committee of the French Society for Microbiology (CA-SFM ${ }^{1}$.

${ }^{1}$ www.sfm-microbiologie.org/
From the RESAPATH database, data regarding E. coli isolates from 2012 to 2016 were extracted. The seven animal species with the largest amount of data were selected: cattle, horse, dog, swine, poultry (Gallus gallus), turkey, and duck. For the analysis, seven antimicrobial categories of relevance in veterinary and human medicine were selected: penicillins, penicillins with beta-lactamase inhibitors, extended-spectrum cephalosporins, aminoglycosides, tetracyclines, folate pathway inhibitors and fluoroquinolones (Table 1). The antibiotics selected were based on antibiotic use in veterinary medicine and on veterinary laboratory practices in France.

Isolates with acquired resistance to at least one antibiotic in three or more antibiotic categories selected were considered as multidrug resistant (Schwarz et al., 2010). MDR proportions and the proportion of isolates with co-resistance to amoxicillin and tetracycline were calculated by animal species and confidence intervals (CI) were estimated using the exact binomial method (two sided $p$-values). The degree of agreement between the number of multidrug resistant isolates and the number of isolates presenting co-resistance to amoxicillin and tetracycline was estimated by calculating the kappa value. Kappa $(k)$ values of $\geq 0.81,0.61-0.80,0.40-0.60$, and $\leq 0.40$ were considered to represent excellent, substantial, moderate to good, and slight to poor agreement, respectively (Viera and Garrett, 2005). R Core Team (2017), R version 3.4.3. (2017-11-30) was used for all statistical analyses.

\section{RESULTS AND DISCUSSION}

A total of 55,904 E. coli isolates were analyzed for the 2012-2016 period (Table 2). MDR varied among animal species, ranging from $21.9 \%$ in horses to $56.0 \%$ in cattle. The proportion of isolates with co-resistance to tetracycline and amoxicillin was the highest for cattle (65.0\%) followed by swine, ducks, and turkeys. The proportion of isolates with co-resistance to amoxicillin and tetracycline was higher than the proportion of multidrug resistant isolates for all food-production animals, but lower for companion animals (dog and horses). These differences are probably due to variations in antibiotic use among animal species (Anses-ANMV, 2018), despite the widespread use of amoxicillin and tetracycline in domestic animals. These elements suggest that the capacity and relevance of the co-resistance to amoxicillin and tetracycline as a proxy for MDR might be linked to the context of antibiotic

TABLE 1 | Antibiotics selected and relative antimicrobial categories used to define multidrug resistance.

\begin{tabular}{ll}
\hline Antimicrobial category & Antibiotic \\
\hline Penicillins & Amoxicillin \\
Penicillins and beta-lactamase inhibitors & Amoxicillin and clavulanic acid \\
Extended-spectrum cephalosporins & Ceftiofur \\
Aminoglycosides & Gentamicin \\
Tetracyclines & Tetracycline \\
Fluoroquinolones & Enrofloxacin or danofloxacin or \\
& marbofloxacin \\
Folate pathway inhibitors & Trimethoprim-sulfamethoxazole
\end{tabular}




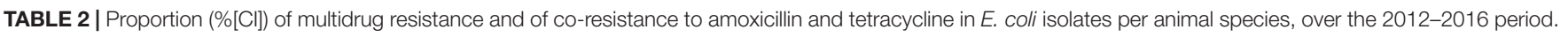

\begin{tabular}{|c|c|c|c|}
\hline Animal species & Number of isolates & Proportion of multidrug resistance & Proportion of co-resistance to amoxicillin and tetracycline \\
\hline Cattle & 21,451 & $56.0[55.4 ; 56.7]$ & 65.0 [64.3; 65.6] \\
\hline Horse & 2,232 & $21.9[20.2 ; 23.7]$ & $17.7[16.1 ; 19.3]$ \\
\hline Dog & 3,226 & $23.3[21.9 ; 24.8]$ & $20.1[18.8 ; 21.6]$ \\
\hline Swine & 5,932 & $44.9[43.6 ; 46.2]$ & $46.7[45.4 ; 48.0]$ \\
\hline Poultry & 16,090 & $22.3[21.7 ; 23.0]$ & 26.0 [25.3; 26.7] \\
\hline Turkey & 4,125 & $24.8[23.5 ; 26.1]$ & $36.5[35.1 ; 38.0]$ \\
\hline Duck & 2,848 & $39.7[37.9 ; 41.6]$ & $45.3[43.5 ; 47.2]$ \\
\hline
\end{tabular}

TABLE 3 | Contingency table of multidrug resistance and co-resistance to amoxicillin and tetracycline in E. coli isolates from all animals considered, over the $2012-2016$ period, with percentages by row (\% R) and by column (\% C).

\begin{tabular}{|c|c|c|c|c|c|}
\hline \multirow{2}{*}{$\begin{array}{l}\text { Profile } \\
\text { Isolates with co-resistance to amoxicillin and tetracycline }\end{array}$} & \multicolumn{2}{|c|}{ Multidrug resistant isolates } & \multicolumn{2}{|c|}{ Non-multidrug resistant isolates } & \multirow{2}{*}{$\begin{array}{l}\text { Total } \\
24,727\end{array}$} \\
\hline & 19,732 & $79.8 \% R$ & 4,995 & $20.2 \% R$ & \\
\hline & & $91.0 \%$ C & & $14.6 \%$ C & \\
\hline \multirow[t]{2}{*}{ Isolates without co-resistance to amoxicillin and tetracycline } & 1,945 & $6.2 \% \mathrm{R}$ & 29,232 & $93.8 \% R$ & 31,177 \\
\hline & & $9.0 \% \mathrm{C}$ & & $85.4 \% \mathrm{C}$ & \\
\hline Total & & 21,677 & & 34,227 & 55,904 \\
\hline
\end{tabular}

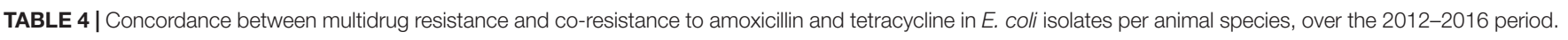

\begin{tabular}{|c|c|c|c|c|c|c|}
\hline $\begin{array}{l}\text { Animal } \\
\text { species }\end{array}$ & $\begin{array}{c}\text { Number of isolates with } \\
\text { co-resistance to } \\
\text { amoxicillin and } \\
\text { tetracycline }\end{array}$ & $\begin{array}{l}\text { Number of } \\
\text { multidrug } \\
\text { resistant } \\
\text { isolates }\end{array}$ & $\begin{array}{l}\text { Number of multidrug } \\
\text { resistant isolates with } \\
\text { co-resistance to amoxicillin } \\
\text { and tetracycline }\end{array}$ & $\begin{array}{l}\text { Proportion of isolates with } \\
\text { co-resistance to amoxicillin } \\
\text { and tetracycline and also } \\
\text { multidrug resistant }\end{array}$ & $\begin{array}{l}\text { Proportion of isolates with } \\
\text { co-resistance to amoxicillin } \\
\text { and tetracycline but not } \\
\text { multidrug resistant }\end{array}$ & $\begin{array}{c}\text { Kappa } \\
\text { value }\end{array}$ \\
\hline Cattle & 13,936 & 12,021 & 11,137 & $79.9 \%$ & $20.1 \%$ & 0.64 \\
\hline Horse & 394 & 489 & 382 & $97.0 \%$ & $3.0 \%$ & 0.83 \\
\hline Dog & 650 & 752 & 572 & $88.0 \%$ & $12.0 \%$ & 0.77 \\
\hline Swine & 2,771 & 2,664 & 2,386 & $86.1 \%$ & $13.9 \%$ & 0.70 \\
\hline Poultry & 4,178 & 3,596 & 3,233 & $77.4 \%$ & $22.6 \%$ & 0.78 \\
\hline Turkey & 1,507 & 1,023 & 983 & $65.2 \%$ & $34.8 \%$ & 0.68 \\
\hline Duck & 1,291 & 1,132 & 1,039 & $80.5 \%$ & $19.5 \%$ & 0.75 \\
\hline
\end{tabular}

use. Similar studies are necessary to confirm these results in area where antibiotic use could be different.

Over the whole period, the concordance between the multidrug resistant E. coli isolates and the isolates with coresistance to amoxicillin and tetracycline was substantial with an overall kappa value of 0.75 , all animals included. More specifically, the concordance was excellent for horses $(k=0.83)$ and substantial for other animal species (Table 3). Calculated per year and all animals included, the degrees of agreement were always substantial, varying between 0.71 and 0.76 over the period.

Based on the contingency table, only $9.0 \%(1,945 / 21,677)$ of multidrug resistant isolates did not display co-resistance to amoxicillin and tetracycline (Table 3). This co-resistance was most frequently associated with other resistances, regardless of the animal species (Tables 3, 4 and Supplementary Tables S1, S2). In fact, among all animals, $79.8 \%(19,732 / 24,727)$ of isolates with co-resistance to amoxicillin and tetracycline were also multidrug resistant (Table 4) and this proportion ranged from $65.2 \%$ for turkeys to $97.0 \%$ for horses (Table 3). However, $20.2 \%$ $(4,995 / 24,727)$ of isolates with this co-resistance did not show other resistances and were not multidrug resistant (Table 4).
In addition, variability among animals was observed (Table 3). Despite these limitations, our findings highlight that, given the widespread use of penicillins and tetracyclines, co-resistance to amoxicillin and tetracycline could be used as a proxy of $\mathrm{MDR}$ in $E$. coli isolates from animals. As the concordance between co-resistance to amoxicillin and tetracycline and MDR is not perfect, this indicator could only be used to approximate MDR proportion.

To constitute a relevant proxy for MDR, the indicator should be a feasible and convenient. In animal health, resistances to amoxicillin and tetracycline are routinely tested by veterinary laboratories (Boireau et al., 2018a) because these antibiotics are among the most frequently used in veterinary medicine (Anses-ANMV, 2018). Finally, because it can be routinely monitored, co-resistance to amoxicillin and tetracycline is both an efficient and relevant indicator of MDR in $E$. coli isolated from animals. Further studies should now evaluate if this indicator remains valid for other bacterial species and in other contexts of antibiotic use. In addition, to confirm and generalize the relevance of co-resistance to amoxicillin and 
tetracycline as an indicator of $\mathrm{MDR}$ in $E$. coli isolates from animals, similar studies performed in other countries and geographical regions are needed.

Moreover, co-resistance to amoxicillin and tetracycline presents several advantages as an indicator. This co-resistance is based on a resistance profile to two pre-defined antibiotics and, consequently, is not related to the total number of antibiotic categories selected for the analysis, contrary to MDR. Using coresistance to amoxicillin and tetracycline will avoid having to take into account a specific number of antibiotic categories for comparison. Since its definition is straightforward (providing no latitude for interpretation), co-resistance to amoxicillin and tetracycline is also easy to calculate.

\section{CONCLUSION}

Beyond the conventional MDR indicator, monitoring resistance associations in animal health would greatly benefit from an easy-to-test indicator of MDR. Because it is based on a specific resistance profile and not on an arbitrary number of resistances and given the widespread use of penicillins and tetracyclines, co-resistance to tetracycline and amoxicillin might be a convenient and reliable indicator to approximate MDR in E. coli isolated from animals. This co-resistance could be routinely monitored to characterize the evolution of resistance' associations over time in E. coli isolates. Any observed changes could then be placed in perspective in terms of therapeutic options in veterinary medicine and public health issues.

\section{DATA AVAILABILITY STATEMENT}

The data used for this study was obtained from the RESAPATH network and the access to data is controlled by the French Agency for Food, Environmental and Occupational Health \& Safety (ANSES). Conditions of approval (respecting the anonymity of farms and laboratories) do not allow us to distribute or make available data directly to other parties.

\section{REFERENCES}

Aarestrup, F. M., Wegener, H. C., and Collignon, P. (2008). Resistance in bacteria of the food chain: epidemiology and control strategies. Expert Rev. Anti Infect. Ther. 6, 733-750. doi: 10.1586/14787210.6. 5.733

Anses-ANMV, (2018). Suivi des ventes de médicaments vétérinaires contenant des antibiotiques en France en 2017. Javené: Anses-ANMV.

Aperce, C. C., Amachawadi, R., Van Bibber-Krueger, C. L., Nagaraja, T. G., Scott, H. M., Vinasco-Torre, J., et al. (2016). Effects of menthol supplementation in feedlot cattle diets on the fecal prevalence of antimicrobial-resistant Escherichia coli. PLoS One 11:e0168983. doi: 10.1371/journal.pone.016 8983

Boireau, C., Cazeau, G., Jarrige, N., Calavas, D., Madec, J.-Y., Leblond, A., et al. (2018a). Antimicrobial resistance in bacteria isolated from mastitis in dairy cattle in France, 2006-2016. J. Dairy Sci. 101, 9451-9462. doi: 10.3168/jds.201814835

\section{AUTHOR CONTRIBUTIONS}

All authors listed have made a substantial, direct and intellectual contribution to the work, and approved it for publication.

\section{FUNDING}

This work was partly supported by the French Ministry of Agriculture (http://agriculture.gouv.fr). No additional external funding was received for this study. The funders had no role in the study design, data collection and analysis, decision to publish or preparation of the manuscript.

\section{TRANSPARENCY DECLARATIONS}

The lead author affirms that this manuscript is an honest, accurate and transparent account of the study being reported; that no important aspects of the study have been omitted and that any discrepancies from the study as planned (and, if relevant, registered) have been explained.

\section{ACKNOWLEDGMENTS}

The authors would like to thank all the RESAPATH laboratories that have been collecting and transmitting antibiogram results for several years. The authors are particularly grateful to Christelle Philippon (RESAPATH's secretary) for her meticulous followup of laboratories and careful data collection and Jean-Luc Vinard (RESAPATH's data architect) for his careful management of the database.

\section{SUPPLEMENTARY MATERIAL}

The Supplementary Material for this article can be found online at: https://www.frontiersin.org/articles/10.3389/fmicb. 2019.02288/full\#supplementary-material

Boireau, C., Morignat, É, Cazeau, G., Jarrige, N., Jouy, É, Haenni, M., et al. (2018b). Antimicrobial resistance trends in Escherichia coli isolated from diseased foodproducing animals in France: a 14-year period time-series study. Zoonoses Public Health 65, 86-94. doi: 10.1111/zph.12412

Chen, X., Zhang, W., Yin, J., Zhang, N., Geng, S., Zhou, X., et al. (2014). Escherichia coli isolates from sick chickens in China: changes in antimicrobial resistance between 1993 and 2013. Vet. J. Lond. Engl. 202, 112-115. doi: 10.1016/j.tvjl. 2014.06.016

Cohen, A. L., Calfee, D., Fridkin, S. K., Huang, S. S., Jernigan, J. A., Lautenbach, E., et al. (2008). Recommendations for metrics for multidrug-resistant organisms in healthcare settings: SHEA/HICPAC position paper. Infect. Control Amp Hosp. Epidemiol. 29, 901-913. doi: 10.1086/591741

Cummings, K. J., Aprea, V. A., and Altier, C. (2015). Antimicrobial resistance trends among canine Escherichia coli isolates obtained from clinical samples in the northeastern USA, 2004-2011. Can. Vet. J. Rev. Vét. Can. 56, 393-398.

De Graef, E. M., Decostere, A., Devriese, L. A., and Haesebrouck, F. (2004). Antibiotic resistance among fecal indicator bacteria from healthy individually 
owned and kennel dogs. Microb. Drug Resist. Larchmt. N 10, 65-69. doi: 10. $1089 / 107662904323047826$

EFSA, and ECDC, (2018). The European Union summary report on antimicrobial resistance in zoonotic and indicator bacteria from humans, animals and food in 2016. Parma: EFSA.

EMA, and ESVAC, (2018). Sales of veterinary antimicrobial agents in 30 European countries in 2016: trends from 2010 to 2016. European Surveillance of Veterinary Antimicrobial Consumption. Amsterdam: EMA.

Ewers, C., Stamm, I., Pfeifer, Y., Wieler, L. H., Kopp, P. A., Schønning, K. et al. (2014). Clonal spread of highly successful ST15-CTX-M-15 Klebsiella pneumoniae in companion animals and horses. J. Antimicrob. Chemother. 69, 2676-2680. doi: 10.1093/jac/dku217

Hanon, J.-B., Jaspers, S., Butaye, P., Wattiau, P., Méroc, E., Aerts, M., et al. (2015). A trend analysis of antimicrobial resistance in commensal Escherichia coli from several livestock species in Belgium (2011-2014). Prev. Vet. Med. 122, 443-452. doi: 10.1016/j.prevetmed.2015.09.001

Karam, G., Chastre, J., Wilcox, M. H., and Vincent, J.-L. (2016). Antibiotic strategies in the era of multidrug resistance. Crit. Care Lond. Engl. 20:136. doi: 10.1186/s13054-016-1320-7

Magiorakos, A.-P., Srinivasan, A., Carey, R. B., Carmeli, Y., Falagas, M. E., Giske, C. G., et al. (2012). Multidrug-resistant, extensively drug-resistant and pandrug-resistant bacteria: an international expert proposal for interim standard definitions for acquired resistance. Clin. Microbiol. Infect. 18, 268-281. doi: 10.1111/j.1469-0691.2011.03570.x
R Core Team (2017). R: A Language and Environment for Statistical Computing. Vienna: R Foundation for Statistical Computing. Available at: http://www.Rproject.org

Schwarz, S., Silley, P., Simjee, S., Woodford, N., van Duijkeren, E., Johnson, A. P., et al. (2010). Assessing the antimicrobial susceptibility of bacteria obtained from animals. Vet. Microbiol. 141, 1-4. doi: 10.1016/j.vetmic.2009.12.013

Strand, L., Jenkins, A., Henriksen, I. H., Allum, A. G., Grude, N., and Kristiansen, B. E. (2014). High levels of multiresistance in quinolone resistant urinary tract isolates of Escherichia coli from Norway; a non clonal phenomen? BMC Res. Notes 7:376. doi: 10.1186/1756-0500-7-376

Viera, A. J., and Garrett, J. M. (2005). Understanding interobserver agreement: the kappa statistic. Fam. Med. 37, 360-363.

Conflict of Interest: The authors declare that the research was conducted in the absence of any commercial or financial relationships that could be construed as a potential conflict of interest.

Copyright (c) 2019 Bourély, Cazeau, Jarrige, Jouy, Haenni, Lupo, Madec, Leblond and Gay. This is an open-access article distributed under the terms of the Creative Commons Attribution License (CC BY). The use, distribution or reproduction in other forums is permitted, provided the original author(s) and the copyright owner(s) are credited and that the original publication in this journal is cited, in accordance with accepted academic practice. No use, distribution or reproduction is permitted which does not comply with these terms. 